\title{
EDUCAC̄̃̃O SUPERIOR DO CAMPO: DESAFIOS PARA A CONSOLIDAÇÃO DA LICENCIATURA EM EDUCAÇÃO DO CAMPO
}

\author{
Salomão Antônio Mufarrej Hage \\ Universidade Federal do Pará (UFPA), Belém - PA, Brasil \\ Hellen do Socorro de Araújo Silva** \\ Universidade Federal do Pará (UFPA), Belém - PA, Brasil \\ Márcia Mariana Bittencourt Brito ${ }^{* *}$ \\ Universidade de Brasília (UNB), Brasília - DF, Brasil
}

RESUMO: $\mathrm{O}$ artigo reflete sobre a educação superior em meio às lutas protagonizadas pelo Movimento da Educação do Campo, a partir da trajetória do Programa de Apoio às Licenciaturas em Educação do Campo (Procampo) no Brasil e no Estado do Pará. O objetivo foi analisar as dificuldades, os desafios e as expectativas demandadas pelos discentes para a consolidação desse curso, por meio de levantamento documental e pesquisa de campo desenvolvida no Campus de Cametá da Universidade Federal do Pará. Os resultados indicaram como dificuldades: a precarização da infraestrutura no desenvolvimento do curso e a pouca aproximação da universidade com os movimentos sociais; como desafios: a importância de os sujeitos compreenderem e assumirem as especificidades do curso e a auto-organização dos estudantes como requisito para sua consolidação; e como expectativas: a necessidade de uma formação diferenciada das práticas convencionais, com ênfase nas experiências socioculturais, e o reconhecimento institucional e social do curso.

Palavras-chave: Educação superior. Educação do Campo. Políticas educacionais. Movimentos sociais. Formação de professores.

http://dx.doi.org/10.1590/0102-4698162036

"Doutor em Educação (PUC), Professor/Pesquisador do Programa de Pós-Graduação em Educação PPGED/ ICED/UFPA. Coordena o Grupo de Estudo e Pesquisa em Educação do Campo na Amazônia. Pesquisador da Rede Universitas/Br desde 2009, na qual participa do Observatório da Educação “Políticas de Expansão da Educação Superior no Brasil", financiado pela Capes. E-mail: < salomao_hage@yahoo.com.br > .

“" Doutoranda em Educação/UFPA, Mestre em Educação pela UEPA. Professora da UFPA, Campus Universitário de Cametá/PA, da Faculdade de Educação do Campo. Participa do Observatório da Educação Superior do Campo, vinculado à Capes, e integra a Rede Universitas/Br. E-mail: < hellen.ufpa@gmail.com> .

"** Doutoranda em Educação/UnB, Mestre em Educação pela UFPA. Especialista em Educação Superior. Pesquisa a Expansão da Educação Superior do Campo, pertence à Rede Universitas/Br desde 2011, é Bolsista na pesquisa do Observatório da Educação "Políticas da Expansão da Educação Superior", financiada pela Capes. E-mail: <marciamarianabittencourt@gmail.com>. 


\title{
HIGHER EDUCATION IN THE COUNTRYSIDE: CHALLENGES FOR THE CONSOLIDATION OF THE DEGREE IN RURAL EDUCATION
}

\begin{abstract}
The article reflects on Higher Education among the struggles led by the peasants' movement of education, from the trajectory of the Support Program Degrees in Rural Education (Procampo) in Brazil and in the State of Pará. The aim was to analyze the difficulties, challenges and expectations demanded by students to consolidate this course, through documentary survey and field research developed in Cametá Campus of the Federal University of Pará. The results indicated as difficulties the precariousness of the infrastructure for the development of the course and a short approach the university with social movements. As challenges, the study has identified the importance of the subjects to understand and assume the course particularities, and self-organization of students as a tool to consolidate the Course. And as expectations, the study has identified the need for the training offered differentiate itself from conventional practice, with emphasis on socio-cultural experiences and the institutional and social recognition of the course.
\end{abstract}

Keywords: Higher Education. Rural Education. Educational Policies. Social Movements. Teachers' formation.

\section{INTRODUĈ̣̃O}

A educação superior do campo no Brasil e no estado do Pará tem se materializado no interior das universidades, pelo vínculo orgânico que as instituições públicas estabelecem com as lutas dos movimentos sociais e com a sua participação no Fórum Nacional e nos Fóruns Estaduais de Educação do Campo. Esses coletivos têm pautado essa modalidade de educação como um direito a ser assegurado aos sujeitos, como demanda para garantir a formação de profissionais que realizam ações de afirmação das escolas públicas de educação básica e de emancipação dos territórios rurais.

Nesse cenário, os cursos de formação de educadores têm se destacado como uma possibilidade de expansão da educação superior do campo, pressionados pelo número ampliado de professores que atuam nas escolas rurais de educação básica somente com o Ensino Médio e/ou Magistério, sem curso de graduação e/ou licenciatura adequada para as disciplinas específicas. No âmbito da Rede Universitas/Br e do Observatório da Educação Superior do Campo, vinculado à Coordenação de Aperfeiçoamento de Pessoal de Nível Superior (Capes), temos realizado nestes últimos anos estudos sobre as políticas de expansão da educação superior nos territórios rurais. 
Nesses estudos consideramos as mudanças econômicas, políticas e sociais em curso e as reformas institucionais do Estado brasileiro ${ }^{1}$ e focamos os processos contra-hegemônicos de formação dos profissionais da Educação e das Ciências Agrárias, refletindo sobre as transformações que desencadeiam no mundo do trabalho e nas escolas de educação básica do campo.

Este artigo é parte dos levantamentos e das análises que temos consubstanciado com a realização dos referidos estudos, focalizando, neste momento, a reflexão sobre as lutas que têm sido protagonizadas pelo Movimento de Educação do Campo no Brasil e no estado do Pará pela educação superior, com destaque para a implementação e o acompanhamento de uma política permanente de formação de educadores e educadoras.

Objetivamos confrontar com as políticas e as propostas hegemônicas de formação pautadas pela intensificação e a precarização do trabalho docente, pela secundarização do conhecimento teórico em face da hipervalorização da prática e pela parceria público-privada como mecanismo para fazer avançar a mercantilização da educação ${ }^{2}$ nos diversos níveis e modalidades de ensino.

$\mathrm{O}$ artigo estrutura-se em quatro partes, assim distribuídas e articuladas entre si: a primeira apresenta as demandas do Movimento da Educação do Campo por políticas de formação dos educadores que contribuam para uma compreensão mais ampliada por parte dos sujeitos camponeses sobre os processos sociais e educacionais nos quais estão inseridos; a segunda apresenta a trajetória do Programa de Apoio à Formação Superior em Licenciatura em Educação do Campo (Procampo) em meio às demandas dos movimentos sociais pela transformação do programa em uma política permanente de formação de educadores; a terceira explicita a natureza e as especificidades da proposta formativa do Curso de Licenciatura em Educação do Campo; e a quarta analisa a implantação do Procampo no estado do Pará, com destaque para as dificuldades, os desafios e as expectativas demandadas pelos discentes do Campus de Cametá da Universidade Federal do Pará, com vistas à consolidação do Curso de Licenciatura em Educação do Campo.

\section{POLÍTICA PÚBLICA DE FORMACุ̃̃O DOS EDUCADORES DO CAMPO NA AGENDA DA EDUCAÇ̃̃O SUPERIOR}

Os movimentos sociais e sindicais do campo nos últimos 18 anos têm se organizado e protagonizado um processo de luta quanto à garantia de seus direitos em âmbito nacional, estadual e municipal, 
articulando as lutas pelo direito a terra com a educação. Esse processo se reconhece nacionalmente como Movimento de Educação do Campo e, no Estado do Pará, como Movimento Paraense de Educação do Campo, que tem no Fórum Paraense de Educação do Campo sua expressão mais significativa de mobilização pela construção de um projeto popular de desenvolvimento e de educação.

Entretanto, em que pese aos esforços dessa mobilização, a universalização da educação básica nos territórios rurais ainda não se concretizou, contrastando com os parâmetros legais existentes e demandando a criação de muitas escolas nesses territórios. Os dados revelam que, das 29.830.007 pessoas que vivem no campo no Brasil (IBGE, 2010), somente $21 \%$ acessam a escola, pois existem apenas 6,3 milhões de matrículas nas escolas rurais, segundo o Censo Escolar do INEP (2011).

No âmbito da formação de educadores, os dados disponibilizados pelo Censo Escolar de 2011 indicam que, dos 342.845 professores que atuam no campo no Brasil, quase a metade - 160.317 - não possui educação superior (46,7\%), e, destes, 156.190 possuem o Ensino Médio $(97,4 \%)$ e 4.127 possuem apenas o Ensino Fundamental (2,6\%).

No caso do estado do Pará, em que pese à implementação do Programa Nacional de Educação na Reforma Agrária (Pronera), do Programa de Apoio à Formação Superior em Licenciatura em Educação no Campo (Procampo) e do Programa Nacional de Formação de Professores (Parfor), desde o início do Movimento de Educação do Campo, no fim dos anos de 1990, os dados revelam que, dos 29.288 professores que atuam nos territórios rurais, apenas 12.815 possuem licenciatura (43,65\%), enquanto 16.473 professores $(56,24 \%)$ atuam sem formação em nível superior (INEP, 2013). Nas comunidades mais distantes das sedes dos municípios, os professores atuam nos anos finais do Ensino Fundamental, ministrando todas as disciplinas no formato de multissérie, sob a alegação de carência de profissionais formados nas diversas disciplinas nessas localidades e do número pouco expressivo de estudantes nas turmas.

As deficiências na formação se agravam quando parte expressiva desses educadores desenvolve o trabalho docente como servidores temporários, sendo contratados por um período de quatro meses, distratados e recontratados continuamente no início e no fim de cada semestre letivo, isentando as prefeituras de efetuar o pagamento de direitos trabalhistas (férias e décimo terceiro salário). Essa situação deixa os educadores vulneráveis e inseguros quanto à permanência no emprego, o que os leva a "mendigar" das autoridades políticas locais vaga para a lotação no semestre letivo. 
Essas peculiaridades se somam ainda às condições pouco adequadas em que os professores do campo desenvolvem o seu trabalho docente, pois grande parte das escolas rurais possui infraestrutura precária e funciona em prédios muito pequenos e em péssimo estado de conservação. Algumas dessas escolas não possuem prédio próprio e funcionam em salões de festas, barracões, igrejas, em um único compartimento, onde se realizam as atividades pedagógicas e outras atividades culturais da própria comunidade.

No período de maior concentração de chuvas, os ramais que dão acesso às escolas rurais ficam intrafegáveis, dificultando o acesso dos professores e encarecendo o valor gasto por eles com transporte para o seu deslocamento, valor esse custeado pelos próprios professores, ainda que a Lei no 11.494 de 2007 (BRASIL, 2007b), que regulamenta o Fundo de Manutenção e Desenvolvimento da Educação Básica e de Valorização dos Profissionais da Educação (Fundeb), estabeleça valores diferenciados quanto ao custo aluno do campo.

Essas situações não estimulam os professores e os estudantes a permanecerem nessas escolas ou a sentirem orgulho de nelas trabalharem/estudarem, fortalecendo o estigma de escolarização rural empobrecida e abandonada e forçando os sujeitos a deslocaremse para estudar na cidade. As referidas situações motivaram o surgimento do Movimento de Educação do Campo, no fim dos anos de 1990, e desde então a criação de uma política pública de formação de educadores emerge como pauta prioritária dos movimentos sociais populares no conjunto de encontros locais, estaduais e nacionais de educação do campo.

A II Conferência Nacional de Educação do Campo (CNEC), realizada em Luziânia-GO, em agosto de 2004, constitui-se num exemplo importante. A declaração final do evento foi assinada por aproximadamente 1.100 representantes de movimentos sociais e das organizações sindicais de trabalhadores do campo e da educação, de universidades, de Organizações Não Governamentais (ONGs) e de Centros Familiares de Formação por Alternância, de secretarias estaduais e municipais de educação e de outros órgãos de gestão pública. Nessa conferência assumiu destaque a formação inicial e continuada dos educadores, assegurada nas universidades públicas de forma gratuita e com o envolvimento dos movimentos sociais:

O que queremos: [...] 3. Valorização e formação específica de educadoras e educadores do campo por meio de uma política pública permanente que priorize: a formação profissional e política de educadores e educadoras do próprio campo, gratuitamente; formação no trabalho que tenha por base a realidade do campo e o projeto político e pedagógico da Educação do Campo; incentivos profissionais 
e concurso diferenciado para educadores que trabalham nas escolas do campo; definição do perfil profissional do educador do campo. (CNEC, 2004, p. 4)

O que vamos fazer: [...] 17. Garantir a formação específica de educadoras e educadores do campo, pelas universidades públicas, pelo poder público em parceria com os movimentos sociais. [...] 19. Investir na formação e na profissionalização dos educadores/das educadoras e outros profissionais que atuam no campo, priorizando os que nele vivem e trabalham. (CNEC, 2004, p. 6)

No desdobramento desse processo, ampliaram-se os marcos regulatórios de reconhecimento da educação do campo como política pública, e foram efetivados programas e ações governamentais que avançam na garantia do direito à educação/escolarização dos sujeitos do campo e contribuem para o fortalecimento das políticas de formação inicial ou continuada dos educadores que atuam nos territórios rurais.

Entre esses marcos regulatórios destacamos as Diretrizes Operacionais para a Educação Básica nas Escolas do Campo, aprovadas por meio da Resolução no 1/2002 CEB/CNE (BRASIL, 2002). No artigo 12 (parágrafo único) foi estabelecido que os sistemas de ensino, em sintonia com o artigo 67 da Lei de Diretrizes e Bases (LDB), devem desenvolver políticas de formação inicial e continuada, habilitando todos os professores leigos e promovendo o aperfeiçoamento permanente dos docentes. Do mesmo modo, o Decreto $\mathrm{n}^{\circ}$ 7.352/2010 (BRASIL, 2010), que dispõe sobre a política de educação do campo e o Pronera, define como um dos princípios "o desenvolvimento de políticas de formação de profissionais da educação para o atendimento da especificidade das escolas do campo, considerando-se as condições concretas da produção e reprodução social da vida no campo" (BRASIL, 2010, art. 2, III).

A partir desses marcos regulatórios, diversos programas voltados para a formação inicial e continuada de educadores e educadoras que atuam nos territórios rurais têm sido implementados e referenciados por experiências educativas protagonizadas pelos movimentos sociais do campo em parceria com as universidades públicas:

- O Programa Nacional de Educaşão na Reforma Agrária foi criado para enfrentar o analfabetismo e elevar os níveis de escolarização de jovens e adultos das famílias beneficiárias dos projetos de assentamento criados ou reconhecidos pelo Instituto Nacional de Colonização e Reforma Agrária em todos os níveis de ensino. Ele promove a formação inicial e continuada dos educadores, especialmente com a oferta dos Cursos de Pedagogia da Terra, das Águas e do Campo e de licenciaturas em várias áreas do conhecimento em todas as regiões brasileiras; 
- O Programa Escola Ativa até 2012 atendeu à formação em serviço dos professores de escolas multisseriadas, tendo sido em 2013 substituído pelo Programa Escola da Terra, o qual promove a formação continuada de professores e professoras que atuam nas escolas multisseriadas rurais e quilombolas através de curso de aperfeiçoamento com a utilização da Alternância Pedagógica;

- O Programa Projovem Campo Saberes da Terra, que se destina à escolarização de agricultores de 18 a 29 anos que não tenham concluído o Ensino Fundamental, concentra suas ações na formação em nível de pós-graduação lato sensu dos educadores e das educadoras que atuam no programa;

- O Programa de Apoio à Formação Superior em Licenciatura em Educação no Campo oferece curso de graduação a professores e professoras das escolas rurais que lecionam nos anos finais do Ensino Fundamental e no Ensino Médio;

- O Programa de Iniciação à Docência para a Diversidade no âmbito do Programa Institucional de Bolsa de Iniciação à Docência concede bolsas para alunos regularmente matriculados nos cursos de Licenciatura para Educação do Campo, em parceria com a Capes, visando fortalecer a ação de formação inicial desses docentes.

Inspirados em sua materialidade de origem na concepção político-pedagógica da educação do campo, esses programas se propõem a ampliar os espaços de formação de educadores como sujeitos históricos sociais, capazes de formar novas gerações com uma perspectiva humanista e crítica, assumindo como princípios formativos: a Alternância Pedagógica com intervenção nas comunidades e nas escolas básicas; a pesquisa como orientação central do curso, pautando a práxis e o trabalho socialmente referenciado pelo cotidiano das comunidades e das escolas rurais (FONEC, 2014).

Considerando os princípios originários do Movimento da Educação do Campo, em sua vinculação com a luta de classes, esses programas promovem uma formação crítica e transformadora, que em vez de formar educadores como intelectuais da disseminação da nova pedagogia da hegemonia, formam educadores formuladores e disseminadores da contra-hegemonia, capazes de promover a necessária articulação das lutas entre as escolas e as lutas para superação dos pilares que sustentam a sociedade capitalista (MOLINA; HAGE, 2015).

No ano de 2012, como desdobramento do Decreto $n^{\circ}$ 7.352/2010 (BRASIL, 2010), a presidente Dilma Rousseff lançou o Programa Nacional de Educação do Campo (Pronacampo), com vistas à implementação de uma política nacional de educação do campo, ao 
englobar e articular as principais ações do governo federal para os povos rurais, oferecendo apoio técnico e financeiro aos entes federados. Esse programa cobra a adesão dos estados, dos municípios e do Distrito Federal, por meio do Plano de Ações Articuladas (PAR), para atender às escolas rurais e quilombolas. No eixo da formação de professores, $\mathrm{O}$ Pronacampo definiu metas ambiciosas para o biênio 2012-2014, para formar 45 mil professores em formação inicial e 100 mil professores em formação continuada na primeira etapa (BRASIL, 2012).

Para o cumprimento dessas metas, o Pronacampo definiu ações como a oferta de cursos de Licenciatura em Educação do Campo, o Plano Nacional de Formação de Professores (Parfor), o Programa Nacional de Assistência Estudantil (PNAES) e o Programa Institucional de Bolsas de Iniciação à Docência (PIBID); cursos de aperfeiçoamento e de especialização e financiamento de pesquisas voltadas para o desenvolvimento da educação do campo e quilombola em Instituições de Educação Superior (IES) públicas e comunitárias; e a expansão dos polos da Universidade Aberta do Brasil (UAB).

O Fórum Nacional de Educação do Campo tem apresentado posicionamento crítico em relação ao Pronacampo. Em um aspecto, reconhece que a amplitude e a abrangência de suas ações têm impactos significativos nos rumos da educação do campo. Em outro, adverte que o Ministério da Educação (MEC), ao privilegiar os entes federativos como interlocutores na implementação das ações, institucionalizou muito o processo, pois, ao restringir o atendimento ao PAR à esfera governamental, encarna historicamente a forma convencional de pensar a política educacional para os territórios rurais, distanciandose das ações e dos sujeitos que historicamente constituíram a prática social identificada como educação do campo (FONEC, 2012).

Na próxima seção, refletiremos sobre o Procampo procurando estabelecer a relação entre os contextos macro e micro que influenciaram a implementação do programa como uma política púbica de caráter permanente.

\section{PROCAMPO: TRAJETÓRIA E DESAFIOS PARA IMPLEMENTAR UMA POLÍTICA PERMANENTE DE FORMAÇÃO}

O Programa de Apoio à Formação Superior em Licenciatura em Educação do Campo é uma política de formação de educadores promovida pelo MEC, por intermédio da Secretaria de Educação Continuada, Alfabetização, Diversidade e Inclusão (Secadi), com apoio da Secretaria de Educação Superior (SESu) e execução financeira 
do Fundo Nacional de Desenvolvimento da Educação (FNDE), em cumprimento às suas atribuições de responder pela formulação de políticas públicas de valorização da diversidade na educação.

Segundo Molina e Sá (2011), a demanda por políticas de formação de educadores tem sido pautada pelos movimentos sociais desde a I Conferência Nacional por uma Educação Básica do Campo, realizada em 1998. No entanto, a exigência de uma política pública para garantir a formação de educadores que atuam nos territórios rurais se consolidou no documento final da II Conferência Nacional de Educação do Campo, realizada em 2004, mencionada anteriormente.

O MEC, por meio da Secretaria de Educação Continuada, Alfabetização, Diversidade e Inclusão, instituiu em 2005 um grupo de trabalho composto por representantes dos movimentos sociais, das universidades e de suas próprias instâncias internas para elaborar subsídios a uma política de formação de educadores do campo, resultando na criação do Procampo, com a implantação dessa nova modalidade de graduação nas universidades públicas em 2007.

A implantação dessa política se deu por meio de uma experiênciapiloto com cursos realizados por meio de convites do MEC a partir de indicações dos movimentos sociais a quatro universidades ligadas à educação do campo: UFMG, UnB, UFBA e UFS. Devido à forte demanda de formação de educadores dos territórios rurais e com a pressão dos movimentos sociais, o MEC lançou editais em 2008 e 2009 para que outras instituições ofertassem a Licenciatura em Educação do Campo, atingindo 32 instituições de ensino superior, que passaram a ofertar o curso sem garantia de continuidade e permanência, pois os editais se efetivaram por meio de projetos especiais autorizados somente para uma turma (MOLINA; HAGE, 2015, p. 17).

A partir do Decreto 7.352/2010 (BRASIL, 2010), que instituiu a Política Nacional de Educação do Campo e definiu metas específicas para a formação de educadores, o MEC lançou o Edital no 02 de 31/08/2012 (BRASIL, 2012), vinculado à SESu/Setec/Secadi/MEC, que aprovou 42 projetos do Procampo apresentados pelas universidades e os institutos federais ${ }^{3}$, para ofertar, cada um deles, 300 vagas regulares na modalidade presencial durante três anos no Curso de Licenciatura em Educação do Campo, totalizando 15.120 vagas para a formação inicial de professores dos territórios rurais. Nesse edital, foram incluídas 15 vagas de concurso para docentes e três para servidores em cada um dos projetos, totalizando 630 vagas de docentes permanentes e 126 de servidores efetivos para atuação específica nos Cursos de Licenciatura em Educação do Campo. O mapa a seguir apresenta as instituições de educação superior onde o curso tem sido ofertado. 


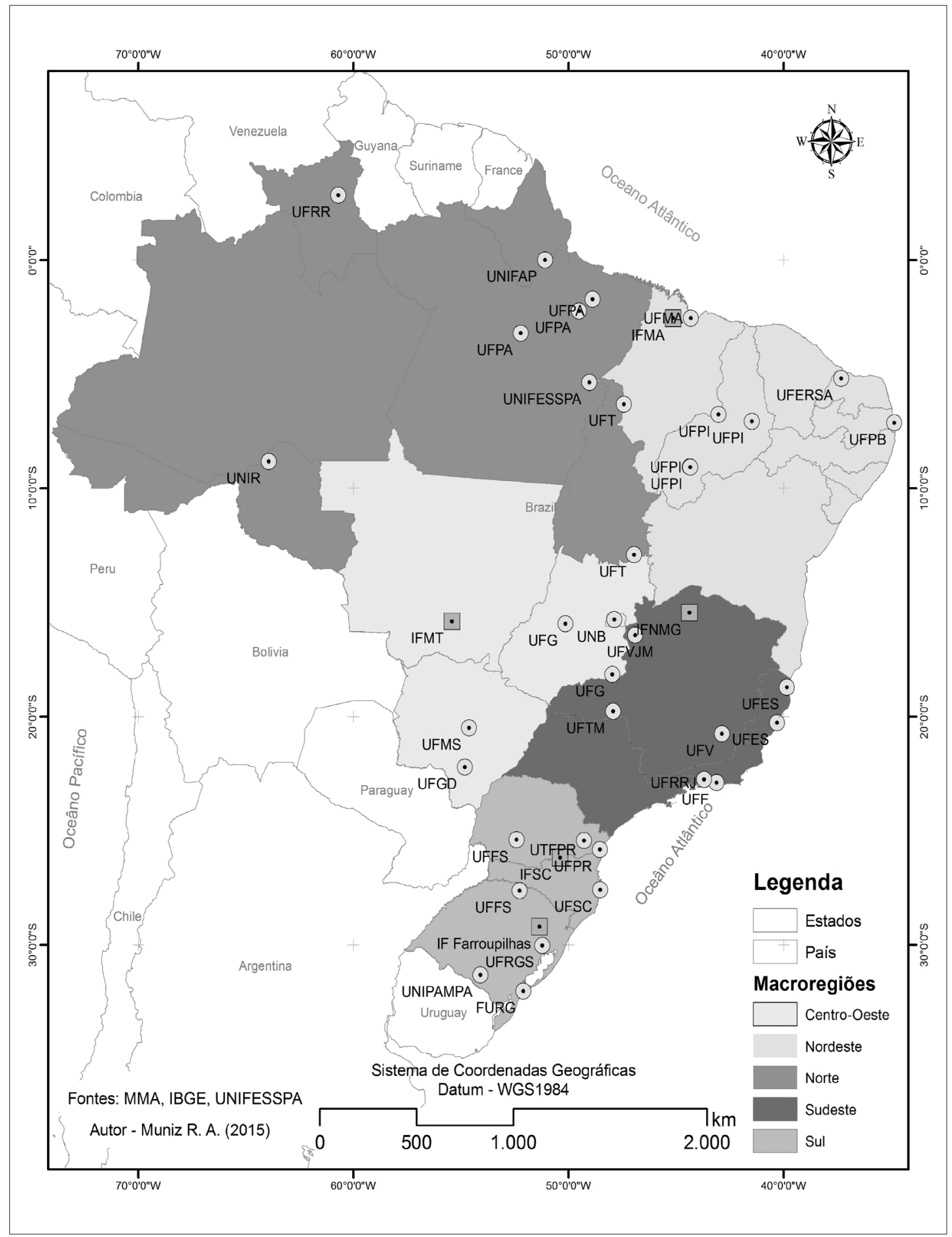


O mapa evidencia a oferta de Cursos de Licenciatura em Educação do Campo em todas as regiões brasileiras e em 24 estados da Federação e no Distrito Federal, à exceção dos estados do Amazonas e do Acre, situação que vem sendo debatida em vários Seminários Regionais e Nacionais específicos do curso de licenciatura em estudo. ${ }^{4}$ Essas situações enfrentadas pelo Procampo nos permitem compreender o processo em que o programa paulatinamente tem se transformado numa política permanente de formação de educadores e segue materializando as expectativas e as reivindicações do Movimento de Educação do Campo.

A reivindicação desse movimento busca assegurar o direito à educação nos territórios rurais por meio de políticas de estado que afirmem seu caráter permanente, republicano e emancipatório enquanto política pública. Assim, para fortalecer essa perspectiva, e em face do aumento de oferta de curso, o Fórum Nacional de Educação do Campo pautou junto com a Secadi/MEC a institucionalização de um Grupo de Trabalho para acompanhar o Procampo (GT-Procampo), instituído pela Portaria $n^{\circ} 1$ de 2/01/2014 (BRASIL, 2014b).

O Grupo de Trabalho tem se afirmado com base nas seguintes atribuições: monitorar a implementação dos cursos relacionados na Portaria $\mathrm{n}^{\circ} 72$ de 21/12/2012; dialogar com o Conselho Nacional de Educação, com vistas à aprovação das Diretrizes Curriculares Nacionais do curso; propor adequações dos Projetos PolíticoPedagógicos dos cursos, a partir dos critérios de avaliação do MEC e do Edital SESu/Secadi/SETEC n 2/2012 (BRASIL, 2012), para fins de reconhecimento dos cursos; e propor iniciativas de ensino, pesquisa e extensão pertinentes à educação do campo e à educação quilombola (BRASIL, 2014a).

Em Nota Técnica produzida pelo GT-Procampo (FONEC, 2014) durante o acompanhamento dos cursos, foram explicitadas referências, princípios e desafios institucionais enfrentados pelo programa, destacando-se as dificuldades e as possibilidades exercitadas nas instituições de educação superior para alcançar o reconhecimento social do Curso de Licenciatura em Educação do Campo. Essas referências, princípios e desafios são aqui explicitados e refletidos em meio à apresentação das especificidades que configuram esse novo curso.

\section{ESPECIFICIDADES DA PROPOSTA FORMATIVA DO CURSO DE LICENCIATURA EM EDUCAÇÃO DO CAMPO}

Os cursos de Licenciatura em Educação do Campo formam educadores e educadoras para atuar na docência por área 
de conhecimento, na gestão das escolas do campo e de processos educativos sociais e comunitários desenvolvidos nos territórios rurais. A construção desse perfil de habilitação articula essas três dimensões, segundo Molina (2014), para promover e cultivar um processo formativo dos futuros educadores com uma formação teórica sólida, que proporcione o domínio dos conteúdos da área de habilitação para a qual se titula o docente; articulada aos conhecimentos sobre as lógicas de funcionamento da escola; de suas funções sociais e das relações que ela estabelece com a comunidade do seu entorno.

Como professores, os estudantes do curso de Licenciatura em Educação do Campo serão habilitados para a docência multidisciplinar nos anos finais do Ensino Fundamental e no Ensino Médio, por meio de uma matriz curricular organizada a partir de quatro áreas de conhecimentos: Artes, Literatura e Linguagens; Ciências Humanas e Sociais; Ciências da Natureza e Matemática; e Ciências Agrárias.

Os conteúdos curriculares para essa formação foram aprovados pelo Conselho Nacional de Educação, por meio do Parecer n ${ }^{\circ}$ 9/2001 - CNE/CP (BRASIL, 2001), sobre as Diretrizes Curriculares Nacionais para a Formação de Professores da Educação Básica, em nível superior, no curso de licenciatura de graduação plena. Essas diretrizes recomendam uma formação mais ampla para educadores que irão atuar nas séries finais do Ensino Fundamental e no Ensino Médio, que ultrapasse os estritos limites disciplinares, ou seja, uma formação por área de conhecimento que favoreça o desenvolvimento de propostas de trabalho interdisciplinar na educação básica (BRASIL, 2001).

Na Nota Técnica do GT-Procampo (FONEC, 2014), a formação dos educadores nessa perspectiva se justifica pela necessidade de ampliar a oferta da educação básica nos territórios rurais, especialmente no Ensino Médio, pois os dados do INEP (2013) apontam que somente de 3\% a 4\% das escolas ofertam regularmente o Ensino Médio, e há um déficit de aproximadamente 200 mil educadores sem graduação nas escolas rurais.

Molina e Sá (2011) acrescentam que a intenção dessa formação diferenciada com suas raízes no Movimento da Educação do Campo é contribuir para a construção de processos que desencadeiem mudanças na lógica de utilização e de produção de conhecimento nos territórios rurais, desenvolvendo ações formativas que visem à compreensão dos sujeitos acerca desses processos.

Outro grande diferencial do curso é a Alternância Pedagógica, que privilegia o reconhecimento de diferentes tempos, espaços e saberes formativos, que se alternam entre Tempo Universidade 
- constituído pelas atividades pedagógicas realizadas nos espaços institucionais de oferta dos cursos - e Tempo Comunidade constituído por ações educativas realizadas nos espaços de trabalho, de militância e de convivência familiar e social dos educandos, ou seja, nas comunidades rurais, nos assentamentos e nos acampamentos, onde a vida concreta dos sujeitos do campo se materializa.

A alternância se constitui num instrumento que aproxima a universidade dos processos de produção de conhecimento que se efetivam nas contradições reais em que os sujeitos materializam sua vida nos territórios rurais. Ela é compreendida como uma estratégia que provoca mudanças substantivas na forma hegemônica de produzir e socializar os conhecimentos, resultante do diálogo entre os conteúdos escolares/acadêmicos e os saberes adquiridos nas práticas produtivas e culturais dos sujeitos do campo, articulando saberes de diferentes tradições: do trabalho, da ciência e da cultura, avançando na perspectiva da interdisciplinaridade e da transdisciplinaridade ao incorporar os saberes dos camponeses na escola.

Segundo Molina e Sá (2012), ao organizar metodologicamente o currículo por alternância entre Tempo Escola e Tempo Comunidade, a proposta do curso objetiva integrar a atuação dos estudantes na construção do conhecimento necessário à sua formação e à sua intervenção como educadores nos espaços formativos escolares e nos tempos de produção da vida nas comunidades rurais. Essas peculiaridades que configuram o Procampo e o Curso de Licenciatura em Educação do Campo vão se materializando com desdobramentos específicos, que se alteram em função dos condicionantes históricos, políticos e sociais e dos cenários que se configuram nas várias regiões e estados da federação, de acordo com o movimento e a participação dos atores sociais que protagonizam o programa e o curso.

A seguir, abordamos as dificuldades, os desafios e as expectativas dos discentes no que concerne à consolidação do curso que vem sendo ofertado pelo Campus de Cametá, da UFPA, desde 2014, após a aprovação de sua proposta no edital de 2012 (BRASIL, 2012), anteriormente mencionado.

\section{DEMANDAS DOS DISCENTES PARA CONSOLIDAÇÃO DA LICENCIATURA EM EDUCAÇÃO DO CAMPO}

No estado do Pará, o Procampo iniciou sua trajetória com a aprovação de 18 turmas de Licenciatura em Educação do Campo nos editais do MEC de 2008 e 2009 e a oferta de 960 vagas pelo Instituto Federal de Educação do Pará (IFPA), distribuídas em vários 
campi nas diversas regiões do Estado. $\mathrm{Na}$ Universidade Federal do Pará, a Faculdade de Ciências Exatas e Tecnologia do Campus de Abaetetuba também aprovou nesses editais uma turma com a oferta de 60 vagas, como demanda do Fórum Regional de Educação do Campo da Região Tocantina II (Forecat).

O referido coletivo reúne entidades de Movimentos Sociais do Campo, Sindicato dos Trabalhadores em Educação, Instituições de Ensino e Pesquisa, órgãos do governo estadual, Secretarias Municipais de Educação e de Agricultura, com o objetivo de pautar políticas públicas de educação e formação permanente dos sujeitos do campo, a partir da dinâmica da agricultura familiar e de seus empreendimentos solidários (BRITO, 2013).

No município de Marabá, o Curso de Licenciatura em Educação do Campo vem sendo ofertado em turmas permanentes desde 2009, no Campus Universitário da UFPA, porém, por meio da Reestruturação e Expansão das Universidades Federais (Reuni), programa do governo federal instituído pelo Decreto Presidencial 6.096 de 24/04/2007 (BRASIL, 2007a), com o objetivo de expandir o acesso e garantir condições de permanência na educação superior federal. Desde então, o curso vem sendo ofertado em regime de Alternância Pedagógica, destacando-se o papel desempenhado pelo Fórum Regional de Educação do Campo do Sul e Sudeste do Pará na construção de sua proposta pedagógica (SEMINÁRIO..., 2015, p. 74).

A partir do edital do MEC/Secadi de 2012, o Curso de Licenciatura em Educação do Campo passou a ser ofertado e financiado por meio do Procampo na Universidade Federal do Sul e Sudeste do Pará (Unifesspa) e na UFPA, nos campi de Abaetetuba, Altamira e Cametá. Foram quatro projetos aprovados nesse edital, totalizando a aquisição de 60 vagas de docentes e 12 de técnicos para o quadro permanente das duas instituições e a oferta de 1.440 vagas para a formação inicial de professores, número pouco expressivo diante dos 16.473 professores que atuam nos territórios rurais sem formação em nível superior existentes no estado do Pará. No âmbito dessas duas universidades, têm-se intensificado as discussões e as ações para que o curso apresente, de fato, uma singularidade referenciada pelas demandas formativas dos territórios rurais da Amazônia.

A experiência do Procampo visa contribuir para a construção coletiva de políticas públicas de educação e formação permanente dos educadores e que fortaleça os vínculos entre a experiência de educação superior e as lutas dos movimentos sociais para transformar o campo num território de garantia de direitos e de afirmação da diversidade. Nos estudos que realizamos sobre as experiências dessas 
instituições, algumas situações têm se apresentado como desafios para o fortalecimento e a consolidação do curso, como: 1) adequação do Projeto Pedagógico do curso para inserção nos sistemas de gestão pedagógica e administrativa das instituições; 2) materialização de uma formação de base unitária, que articule os saberes e as experiências culturais dos sujeitos do campo com os conhecimentos resultantes dos avanços da ciência e da tecnologia, na perspectiva da formação humana e profissional dos estudantes.

Esses e outros desafios se manifestam com especificidades próprias, que emergem dos condicionantes políticos, econômicos e culturais que configuram a oferta do curso nas duas universidades, sobretudo quando consideramos a diversidade de ênfases ou habilitações definidas nos projetos pedagógicos dos cursos. A Unifesspa oferta as quatro áreas de conhecimento - Ciências Humanas e Sociais; Ciências Agrárias e da Natureza; Letras e Linguagens; e Matemática. Quanto à UFPA, o Campus de Altamira oferta as áreas de Ciências da Natureza e Linguagem e Códigos; o Campus de Abaetetuba oferta as áreas de Ciências Naturais, Matemática e Linguagem, Códigos e Suas Tecnologias; e o Campus de Cametá oferta a área de Ciências Agrárias e da Natureza com habilitação em Biologia e Química.

Para a abrangência deste artigo, priorizamos os dados sobre a experiência do Curso de Licenciatura em Educação do Campo ofertado pelo Campus de Cametá da UFPA, extraídos a partir dos documentos: Projeto Político-Pedagógico do Curso; legislação referente ao programa e ao curso, com destaque para os editais de criação do programa e do processo seletivo diferenciado para o ingresso dos estudantes; e textos com relatos de experiência do curso.

A pesquisa de campo teve como lócus uma turma em funcionamento no município de Cametá, onde realizamos observação das atividades acadêmicas de duas disciplinas do curso durante o primeiro Tempo Universidade e aplicamos um questionário para identificação do pertencimento social dos discentes e construção do perfil da turma; na coleta desses dados, vale enfatizar que todos os sujeitos responderam ao questionário solicitado. A turma investigada era formada por 35 estudantes aprovados no processo seletivo especial (Edital no 11/2013), destinado à seleção diferenciada, como especificidade do curso em estudo.

Entre os estudantes da turma, 63\% eram homens e 37\% eram mulheres. Em relação ao pertencimento social, 34\% dos estudantes se autodefiniam como agricultor familiar; $23 \%$, pescador; $17 \%$, ribeirinho; e $26 \%$ se reconheciam como pescador-ribeirinho-agricultor familiar. 
Sobre a escolarização dos discentes, $71 \%$ haviam cursado o Ensino Fundamental em escola rural, 26\% tinham concluído esta etapa de ensino em escola urbana e 3\% haviam estudado os anos iniciais em turma multisseriada e os anos finais na sede do município para a conclusão da etapa de ensino. Em relação ao Ensino Médio, 34\% o haviam cursado por meio do Sistema Modular de Ensino (Some), e a mesma porcentagem, nas Escolas Públicas da Rede Estadual. Identificamos ainda que $12 \%$ cursaram o Magistério e $20 \%$ cursaram o Ensino Médio na modalidade Educação de Jovens e Adultos (EJA) na Casa Familiar Rural. Quanto ao Ensino Superior, $69 \%$ dos discentes ingressaram na universidade pela primeira vez, e $31 \%$ já possuíam graduação ou a cursavam em universidade privada.

Posteriormente, realizamos entrevista coletiva com 12 discentes que se dispuseram a participar de duas rodas de conversa sobre as dificuldades, os desafios e as suas expectativas quanto à consolidação do curso, tendo como critério de escolha dos sujeitos a adesão voluntária após a apresentação do estudo, quando assinaram o Termo de Consentimento Livre e Esclarecido. A identificação dos discentes no fim de cada um dos depoimentos se deu por meio de nomes fictícios, acrescidos da idade e do município de origem dos estudantes.

Os discentes entrevistados são provenientes dos municípios de Cametá, Igarapé-Miri, Oeiras do Pará, Limoeiro do Ajuru e Mocajuba, residentes em diversas comunidades rurais, localizadas a uma distância de até 70 quilômetros da cidade de Cametá, no território do Baixo Tocantins. Este território é marcado por contrastes evidenciados pelos conflitos entre a dinâmica instituída com a presença de grandes projetos e empreendimentos - como Albras/Alunorte, Biopalma e Agropalma - e as práticas produtivas advindas da pesca artesanal, da agricultura familiar camponesa e do extrativismo.

No período da pesquisa, os discentes se encontravam no segundo Tempo Universidade do primeiro ano do curso de Licenciatura em Educação do Campo no Campus de Cametá/UFPA. O curso está vinculado à Faculdade de Educação do Campo, e sua implantação advém da participação da universidade no Fórum de Educação do Campo, das Águas e da Floresta da Região Tocantina (Fecaf) e no Fórum Paraense de Educação do Campo (FPEC). Estes coletivos reúnem movimentos sociais, órgãos públicos, universidades e institutos federais, professores e estudantes das escolas rurais e Organizações Não Governamentais (ONGs) para lutar pela afirmação de uma sociedade camponesa de base agroecológica e pela garantia dos direitos sociais e educacionais dos povos do campo da Microrregião do Baixo Tocantins e do estado (UFPA, 2013). 
A estrutura curricular compõe-se de três núcleos centrais: Núcleo Contextual, Núcleo Estrutural e Núcleo Integrador, constituídos por atividades acadêmicas, científicas e culturais e complementados com estágios curriculares supervisionados.

Esses núcleos estão organizados em cinco eixos, que se articulam para ofertar a formação na área de Ciências Agrárias e da Natureza com habilitação em Biologia e Química. São eles: I - Educação do Campo, Ciência e Movimentos Sociais; II Fundamentos Teóricos e Metodológicos da Educação; III - Bases Fundamentais das Ciências da Natureza; IV - Ciências da Natureza e Suas Tecnologias; e V - Educação do Campo e Economia Solidária (FONEC, 2015). Os referidos eixos se integralizam nos quatro anos de oferta do curso, distribuídos em sete alternâncias pedagógicas, que se materializam entre Tempo Universidade e Tempo Comunidade.

A estrutura curricular oportuniza aos discentes a vivência da pesquisa como princípio educativo e a produção de conhecimentos ancorada no diálogo entre os saberes acadêmico-científicos e os saberes da cultura vivida pelos sujeitos do campo, as quais circulam em suas comunidades, em movimentos sociais, fóruns, associações e sindicatos em que se inserem.

Essas especificidades vão sendo apropriadas pelos estudantes durante as alternâncias pedagógicas, e nesse processo emergem dificuldades, desafios e expectativas que eles mesmos foram pontuando durante as entrevistas e que os motivam a permanecer no curso. Os depoimentos a seguir apresentados expressam as principais dificuldades que os estudantes vêm enfrentando no curso desde sua implantação no Campus de Cametá/UFPA.

O curso foi construído na pauta do movimento, pois se exigia uma educação diferenciada. Em nossa realidade o movimento de educação do campo [...] se constrói pelo movimento sindical que abraça essa luta, então vejo que é uma construção, e a luta do movimento social tem algumas dificuldades na execução, então o curso precisa estar em sintonia com os princípios que possibilitaram sua realização. (João, 28 anos, estudante do município de Mocajuba)

Quando fizemos o processo seletivo tínhamos como garantia alimentação, hospedagem e passagem, porém a hospedagem e alimentação nunca foram garantidas para todos, isso tem sido uma grande dificuldade para quem não tem uma renda fixa, porque temos que conciliar as aulas do curso com a manutenção de alimentação e hospedagem nossa na universidade e também garantir o sustento de nossa família, isso é um fator que dificulta a permanência nas aulas. Em relação à questão pedagógica, iniciamos muito bem na primeira etapa do curso, pois tivemos um direcionamento para o tempo comunidade, porém neste segundo Tempo Universidade encontramos professor que falta muito, interrompe as aulas, isso nos deixa totalmente prejudicados no pouco tempo que temos, e como é um curso em alternância não podemos estarperdendo muito. (José Carlos, 33 anos, estudante do município de Cametá) 
Vejo que nesse momento do curso as dificuldades são muitas, pois parece que a universidade está pensando uma estrutura mais para ela, então isso faz a gente ver que quando se lançou o edital do vestibular, penso que não foi somente para educar as pessoas do campo, mas para que viesse mais recurso para as universidades também, pois tem se falado em muitas vagas para professor. A essência da coisa é que as pessoas que estão na estrutura da universidade e que estão para construir essa política de educação do campo não estão bem esclarecidas como pensávamos. Percebemos falas superficiais sobre o PPC [Projeto Pedagógico de Curso] do curso. O que tem nos deixado muitas dúvidas, principalmente sobre como será nossa atuação no mercado de trabalho. (Márcio, 29 anos, estudante do município de Igarapé-Miri)

Acredito que o professor antes de vir para sala de aula deveria passar por um processo de formação, para que o curso tenha um direcionamento na concepção. Pois teve professor que chegou a afirmar que não poderíamos ter uma flexibilidade de horário, teríamos que ter postura acadêmica e que em relação a outro curso, nos éramos uma turma inferior na questão do conhecimento. Então, essas coisas, o professor deveria ter a base. (Maria José, 24 anos, estudante do município de Cametá)

Em síntese, os estudantes indicam como dificuldades: a infraestrutura para o desenvolvimento das atividades do curso e a pouca aproximação da universidade com os movimentos sociais entendida como a compreensão e a relação de gestores, professores e estudantes do curso com a trajetória e as demandas dos movimentos sociais quanto às políticas educacionais.

Além disso, eles destacam que as longas distâncias existentes entre as comunidades rurais onde residem e trabalham (seja nas escolas de educação básica, na roça, na pesca, no extrativismo ou nas atividades de assessoria e organização de grupos e coletivos) e as dependências da universidade onde se realizam os Tempos Universidades acabam por dificultar ainda mais o acesso e a permanência dos estudantes.

Associa-se a isso o baixo poder aquisitivo dos estudantes, incluindo ainda a necessidade de custear suas famílias nos momentos em que precisam estudar, pois os jovens que participam do curso possuem suas próprias famílias ou são parte da força produtiva de sua família. Isso implica um esforço a mais para permanecerem no curso e para custear sua manutenção no Tempo Universidade.

A realização do Tempo Comunidade também requer uma logística nem sempre assegurada no orçamento das universidades para o provimento de diárias, transporte, alimentação e aquisição de material para experimentação, de modo a oportunizar que os estudantes e os professores participem e desenvolvam as atividades de campo nas escolas ou nos espaços comunitários.

Esses fatores constituem-se como condicionantes que podem inviabilizar a permanência, a aprendizagem e a conclusão do curso pelos estudantes. Segundo Mancebo (2015), tais dificuldades têm se 
intensificado nas universidades públicas após a implantação do Reuni, que, por um lado, expandiu a rede pública, com o aumento de $70 \%$ das matrículas presenciais na rede federal entre 2007 e 2013, mas, por outro, introduziu os contratos de gestão no interior das universidades públicas, resultando em prejuízos aos processos de ensino, pesquisa e extensão ao condicionar o financiamento dessas IES à execução de metas de expansão de vagas discentes e de reestruturação político-pedagógica, exigindo-se a superutilização dos recursos existentes nas universidades federais com um incremento pífio das verbas de custeio e pessoal.

Como mencionado, a falta de entendimento por parte de professores, gestores, servidores e estudantes em relação às especificidades e às intencionalidades que configuram o Procampo no contexto da educação do campo também foi destacada pelos sujeitos entrevistados como uma dificuldade sentida durante a efetivação do curso. Eles mencionaram a distância de determinados professores quanto à proposta do curso, às intencionalidades configuradoras de seu projeto político-pedagógico e as suas implicações para o trabalho docente, como a rigidez com que se posicionam quanto ao horário, ao conteúdo curricular e à utilização da dinâmica metodológica referenciada pela Alternância Pedagógica, que demanda o trabalho coletivo para o alcance dos objetivos.

Os posicionamentos pouco consistentes desses professores desencadeiam dúvidas e inseguranças nos estudantes sobre: a consistência teórica da formação ofertada pelo curso; a pertinência da proposta metodológica e sua competência acadêmica em relação à formação dos discentes de outros cursos; e sua atuação como egressos no mercado de trabalho, em face de a proposta pedagógica encontrarse em fase de reconhecimento na universidade e na sociedade.

Essas situações são fatores limitadores para a consolidação do curso, pois o Movimento da Educação do Campo vem demandando dos processos de formação dos educadores que considerem as contradições sociais, políticas, econômicas e culturais enfrentadas pelos sujeitos nos territórios rurais e que os instrumentalizem no enfrentamento e na superação dessas contradições.

Molina e Sá (2012) evidenciam essa intencionalidade, esclarecendo que, na execução dessa licenciatura, deve-se partir da compreensão da necessária vinculação da educação do campo com a vida dos sujeitos envolvidos nos processos formativos, abrangendo suas condições de vida, trabalho e cultura, sendo que o curso não pode, por isso, ser subsumido numa visão de educação que se reduza à escolarização.

Assim, a utilização do curso para ampliação do quadro de docentes permanentes na universidade ou para suprir as deficiências 
estruturais face aos contingenciamentos do orçamento público termina por enfraquecer a potencialidade do Procampo de ser assumido como uma política permanente de formação de educadores do campo, situação que pode ser enfrentada com o fortalecimento dos vínculos com os coletivos e as entidades de movimento social e sindical onde o curso é ofertado.

Os estudantes entrevistados também foram indagados sobre os desafios enfrentados no momento de implantação do curso, tendo destacado a importância de os sujeitos participantes do curso compreenderem e assumirem as inovações nele propostas. Nessas propostas se incluem: a Alternância Pedagógica como estratégia teórico-metodológica utilizada na formação dos educadores; e a auto-organização dos estudantes como instrumento para fortalecer a cultura acadêmica no curso. Essas questões podem ser mais claramente identificadas nas falas a seguir apresentadas.

O curso tem despertado novas ideias, novos olhares e é muito desafiador, estou muito esperançoso com o curso. Na primeira etapa, foi muito importante o trabalho na comunidade, muitas coisas surgiram na investigação, vejo que vamos ter que nos doar, pois essa bandeira também é nossa. Já era dentro dos sindicatos e até mesmo com as prefeituras e agora volta a ser um debate mais tenso, pois agora estamos dentro do curso e para conquistar nossos espaços na universidade, tem sido e será um processo muito duro. (João, 28 anos, estudante do município de Mocajuba)

É bem interessante a questão da alternância, do trabalho que temos que desenvolver na comunidade, mas a socialização, precisa ser construída de forma mais abrangente, mais divulgada, deve-se fazer um evento para que seja divulgado para sociedade local. Nós trouxemos temas importantes, como: merenda escolar, agricultura familiar, cada um trouxe um tema de sua comunidade e vejo que isso é o diferencial e o nosso desafio é que devemos fazer essa volta para a comunidade, já iniciamos um trabalho para que possamos apresentar. Esse retorno para a comunidade precisa acontecer. (Paulo, 45 anos, estudante do município de Limoeiro do Ajuru)

Vejo que nós estamos no caminho certo, do ponto de vista organizativo, pois já começamos a discutir a formação do Centro Acadêmico dentro do nosso curso, e assim passaremos a ter uma ferramenta jurídica para poder chegar nos departamentos que temos dentro da universidade ou até mesmo na reitoria para buscar algum benefício para nós. A turma está bastante avançada do ponto de vista da organiz̧ação, de uma etapa para outra a turma adquiriu maturidade e os alunos estão apoiando a nossa organização, estamos saindo desta etapa com o encaminhamento de articular com os outros polos de formação como Oeiras do Pará e Baião. Tudo isso é justamente para fortalecer nossa relação acadêmica. (Francisco, 40 anos, estudante do município de Oeiras do Pará)

Assim, entre os desafios apresentados para a consolidação do curso, os estudantes destacaram inicialmente a necessidade de que os sujeitos que participam e constroem os cursos - professores, gestores, servidores e estudantes - compreendam as inovações e as singularidades 
contidas na proposta da Licenciatura em Educação do Campo, que propõe formar educadores e educadoras com formação teórica sólida, para atuar como professores das áreas de conhecimento, como gestores das escolas do campo e como educadores sociais nas comunidades rurais.

De fato, o Movimento da Educação do Campo, desde sua criação, tem reivindicado que os processos de formação docente devem priorizar a formação humana dos educadores para se colocarem como agentes participativos na construção de um novo projeto de desenvolvimento para o país, que afirme o lugar do campo nesse novo projeto (MOLINA; HAGE, 2015). Para tanto, faz-se necessário que, nos processos formativos que se efetivam com o Curso de Licenciatura em Educação do Campo, os educadores e as educadoras se apropriem do domínio dos conteúdos escolares, articulado à compreensão do funcionamento e da função social da escola e de suas relações com todos os espaços educativos existentes nos territórios rurais.

Assim sendo, os desafios assinalados pelos estudantes indicam a necessidade de entender a escola em sua complexidade e suas contradições, quanto à socialização de conteúdos, experiências, valores e padrões de socialibilidade, que convergem para a manutenção ou a transformação da sociedade, para fortalecer a hegemonia ou construir a contra-hegemonia. Nesse contexto, a escola precisa ser entendida e materializada em sintonia com os espaços e os processos formativos que se efetivam nas comunidades e nos territórios rurais, dialogando com essas experiências e reconhecendo o valor de sua contribuição para a formação da identidade dos sujeitos e para a disputa dos projetos sociais e políticos existentes.

Com relação à Alternância Pedagógica, há o reconhecimento de que oportuniza o diálogo entre teoria e prática e de que motiva os estudantes a investigarem a realidade e a levantarem os problemas enfrentados pelos sujeitos do campo no trabalho, nas escolas de educação básica e nas demais experiências formativas em suas comunidades. Ela oportuniza a construção de diagnósticos que devem provocar o retorno dos estudantes para essas comunidades e sua intervenção referenciada pelo conhecimento dos condicionantes sociais, políticos, econômicos e culturais que configuram a vida, o trabalho e as culturas nos territórios rurais.

Outra questão apresentada como desafio foi o processo de auto-organização e mobilização dos estudantes, indicado como uma estratégia para assegurar a estrutura e os recursos necessários para materializar a dinâmica e as ações que vêm se efetivando por meio do curso no interior da universidade e nas próprias comunidades rurais. O enfrentamento dos desdobramentos resultantes dos 
contingenciamentos no orçamento e da não compreensão por parte das instâncias acadêmicas acerca dessas especificidades demanda a organização dos estudantes para reivindicá-las e assegurá-las.

A iniciativa da organização se coaduna com a proposição de Pistrak (2011) e de intelectuais que são referência no Movimento da Educação do Campo e na construção da Pedagógica do Movimento (CALDART, 2011). Isso porque assumem que as experiências formativas da escola, em qualquer nível ou etapa de ensino, devem promover a auto-organização dos estudantes, implicando a constituição de coletivos infantis e juvenis para realizar ações práticas e de intervenção na realidade concreta, não como um jogo, mas como uma ocupação séria, encarregada de responsabilidades sentidas e compreendidas, que fortaleça a formação política e geral dos estudantes.

Essa compreensão se insere no conjunto de referências que orientaram a criação do curso, assim como as demais experiências formativas reivindicadas e assumidas pelo Movimento de Educação do Campo, de que, para transformar a escola, e para colocá-la a serviço da transformação social, não basta alterar os conteúdos nela ensinados. É preciso mudar o jeito da escola, suas práticas e sua estrutura de organização e funcionamento, tornando-a coerente com os novos objetivos de formação de cidadãos, capazes de participar ativamente do processo de construção da nova sociedade (CALDART, 2011; PISTRAK, 2011).

Por último, os discentes, durante as entrevistas realizadas, apresentaram em seus depoimentos suas expectativas em relação ao curso, pontuando a necessidade de que a formação oferecida se diferencie das práticas formativas convencionais existentes, atribuindo importância à valorização de suas vivências e experiências e à necessidade de reconhecimento institucional e social do curso:

É o primeiro curso que vem para formar os professores do campo, e que nós não sejamos meros professores que vão se formar e reproduzir o que já vem sendo feito nas escolas. Pode ter sim um grande interesse por trás de nosso curso, mas o dever de cada um de nós é lutar, pois temos uma perspectiva. Devido essas questões financeiras muitos pensaram em desistir, mas estão aqui e dependem sim muito de nós, pois viemos de muitas dificuldades, mas que possamos voltar para nossa comunidade e fazer a diferença. (Joana, 27 anos, estudante do município de Cametá)

Antes eu não tive interesse por outra licenciatura, porque o men foco era a agricultura, sempre fui do movimento social e ai eu vi na licenciatura em educação uma possibilidade de contribuir com essa realidade. Quando me vejo hoje aqui na universidade, passa um filme na minha cabeça, pois quem morava e mora em comunidades mais distantes não tinha muita opção, faz̧ia até a quarta série ou parava, ou vinha morar na cidade, mas o curso pode ser uma resposta e vai depender de cada um de nós, pois não adianta ter o curso 
somente como um depósito, temos que fazer as informações chegar em nossa comunidade, nos sindicatos, nas cooperativas e hoje já podemos contribuir com um conhecimento mais técnico e qualificado. (Paulo, 45 anos, estudante do município de Limoeiro do Ajuru)

Em relação à questão pedagógica, esperamos muito dos coordenadores e de nossos professores e de nós enquanto alunos da turma. Como educando vejo como uma oportunidade impar em estar contribuindo desde já nas nossas comunidades e conseguir que o curso de educação do campo, tanto na área das agrárias quanto das ciências naturais seja incluído na pauta de concurso público no diálogo com as prefeituras. A proposta pedagógica do curso é um processo em construção e nós vamos percebendo o diferencial nos professores que já vêm nessa construção. E não vejo que temos que fechar as portas para quem não vem dessa relação com o campo, pois é um processo de aprendizagem. Mas nossa expectativa é que toda a vivência que temos com o campo seja considerada, pois muitos de nós vêm de um intenso envolvimento com os movimentos sociais e isso precisa ser levado em consideração e respeitado. (Francisco, 40 anos, estudante do município de Oeiras do Pará)

Os estudantes manifestaram como expectativa que as práticas formativas dos educadores no curso contribuam para transformá-los em agentes de mudança no interior das escolas e das comunidades rurais, para que possam fazer a diferença ao socializarem e fazerem informações, conhecimentos, tecnologias e práticas significativas e qualificadas circularem, fortalecendo as escolas de educação básica e os coletivos existentes nos territórios rurais, como: sindicatos, cooperativas e associações de produtores e organizações sociais, religiosas, culturais e comunitárias.

Eles também pontuaram a importância do reconhecimento e da incorporação, nos processos educativos desenvolvidos pelo curso, de suas vivências e experiências acumuladas com a participação nesses mesmos coletivos e organizações existentes nos territórios rurais, pois muitos estudantes já atuam como educadores nas escolas de educação básica ou como lideranças dos movimentos sociais e das organizações sindicais, culturais, religiosas e comunitárias. Para esses estudantes, o curso pode se tornar um espaço importante de enfrentamento do entendimento generalizado de que é preciso sair do campo para continuar os estudos, para cursar a universidade, quando ele oportuniza aos sujeitos estudar, trabalhar e continuar militando nos coletivos, nas entidades e nas organizações existentes nos territórios e nas comunidades rurais.

Outra questão pontuada nos depoimentos e também na Nota Técnica do GT-Procampo (FONEC, 2014) refere-se à necessidade de reconhecimento institucional e social do curso, o que implica a inserção do perfil do licenciado em Educação do Campo nos editais de concursos públicos realizados pelas esferas estadual, federal e municipal para concorrer às vagas para docentes, coordenadores pedagógicos e gestores nas escolas rurais. 
De fato, desde que o curso de Licenciatura em Educação do Campo foi criado, em 2007, e mais propriamente com a conclusão das primeiras turmas, os egressos do curso enfrentam dificuldades para atuar como professores do quadro efetivo das redes de ensino nos anos finais do Ensino Fundamental e no Ensino Médio. Especialmente porque essas redes organizam o ensino nessas etapas de forma predominantemente disciplinar, e a formação ofertada pelo curso habilita os estudantes para a docência multidisciplinar, nas quatro áreas de conhecimento anteriormente mencionadas. Essa questão tem sido incluída na pauta dos estudantes cursistas ou egressos nos coletivos, que vão se formando a partir de sua autoorganização ou em conjunto com as universidades que ofertam os cursos, e em articulação com os fóruns e os comitês regionais, estaduais e nacional de educação do campo.

Nesses momentos são debatidas e afirmadas as potencialidades do curso de Licenciatura em Educação do Campo e o perfil de seus egressos com diferentes órgãos gestores e executores da educação nas esferas federal, estaduais e municipais, em que se incluem o Conselho Nacional de Secretários de Educação (Consed), a União Nacional dos Dirigentes Municipais de Educação (Undime), a Coordenação de Aperfeiçoamento de Pessoal de Nível Superior (Capes) e o próprio MEC, com seus órgãos e secretarias que atendem à educação do campo no nível superior (FONEC, 2014).

\section{CONSIDERACְÕES FINAIS}

Ao longo deste artigo, apresentamos inúmeras reflexões sobre as lutas que têm sido protagonizadas pelo Movimento de Educação do Campo para a implementação de uma política permanente de formação de educadores e educadoras. Essas reflexões se confrontam com as políticas e as propostas hegemônicas de formação de educadores atualmente existentes ao contribuírem para uma compreensão mais ampliada por parte desses sujeitos acerca dos processos sociais e educacionais nos quais estão inseridos.

Tomamos como foco de análise a trajetória do Programa de Apoio à Formação Superior em Licenciatura em Educação do Campo no Brasil e no Estado do Pará, explicitando a natureza, as especificidades e as potencialidades do curso de Licenciatura em Educação no Campo e o perfil de seus egressos em meio às demandas dos movimentos sociais pela transformação do programa numa política permanente de formação de educadores e educadoras 
do campo. Por último, analisamos as dificuldades, os desafios e as expectativas demandadas pelos discentes do Campus de Cametá da Universidade Federal do Pará com vistas à consolidação do Curso de Licenciatura em Educação do Campo.

Entre as dificuldades enfrentadas pelos estudantes, a precarização da infraestrutura para o desenvolvimento das atividades do curso foi ressaltada, apresentando-se como um fator que pode inviabilizar a permanência, a aprendizagem e a conclusão do curso pelos estudantes. A pouca aproximação de gestores, professores e estudantes com a trajetória e as demandas políticas educacionais dos movimentos sociais do campo também foi pontuada como um limitador para a consolidação do curso, uma vez que interfere nos processos de formação de educadores, desencadeando dúvidas e inseguranças nos estudantes sobre a consistência teórica e a pertinência da proposta metodológica do curso e suas implicações na formação acadêmica em relação aos discentes de outros cursos e na indefinição de atuação dos egressos no mercado de trabalho.

Entre os desafios apresentados pelos estudantes para a consolidação do curso foi destacada a importância de os sujeitos nele envolvidos compreenderem e assumirem as inovações propostas. Entre estas, sobressai-se a Alternância Pedagógica, utilizada como estratégia teórico-metodológica que oportuniza o diálogo entre teoria e prática e que motiva os estudantes a investigarem a realidade e a intervirem nos problemas enfrentados pelos sujeitos do campo no trabalho, nas escolas de educação básica e nos demais espaços e experiências formativas das comunidades rurais.

A auto-organização dos estudantes também foi pontuada como desafio para o fortalecimento da cultura acadêmica no interior do curso. É compreendida como uma estratégia para assegurar a estrutura e os recursos necessários para materializar a dinâmica e as ações do curso na universidade e nas próprias comunidades rurais.

Entre as expectativas dos discentes pontuadas com vistas à consolidação do curso, destacou-se a necessidade de que a formação nele oferecida se diferencie das práticas formativas convencionais. Desse modo, deve reconhecer, valorizar e incorporar as vivências e as experiências dos estudantes acumuladas com a participação nos coletivos e nas organizações existentes nos territórios rurais e formar os educadores do campo como agentes de mudança no interior das escolas e das comunidades rurais.

Por fim, os alunos ressaltaram a necessidade de inserção do perfil do licenciado em Educação do Campo nos editais de concursos 
públicos realizados pelas esferas estadual, federal e municipal para educadores das escolas rurais. Essa questão é entendida como um passo decisivo para a afirmação e a consolidação do curso no interior da universidade e na sociedade.

O Curso de Licenciatura em Educação do Campo, em nossa visão, encontra-se em processo de implementação, decorrendo dessa situação inúmeras dificuldades quanto aos aspectos administrativos e financeiros, o que tem motivado os questionamentos dos estudantes quanto à garantia dos direitos explicitados no edital do processo seletivo especial.

Outro ponto a ser enfatizado refere-se à especificidade da formação dos educadores, que tem se construído por área de conhecimento e com base na Alternância Pedagógica. Essas questões têm apresentado muitos desafios e expectativas na busca pela consolidação do Curso de Licenciatura em Educação do Campo como uma política permanente nas universidades públicas, que garanta o direito dos povos do campo à educação superior.

\section{REFERÊNCIAS}

BRASIL. Grupo Permanente de Trabalho sobre Educação do Campo. Referências para uma política Nacional de Educação do Campo. Brasília, 2014a. Diário Oficial da União, Brasília, n. 2, Seção 1, p. 83, jan. 2014.

Decreto n. 6.096, de 24 de abril de 2007. Institui o Programa de apoio a Planos de Estruturação e Expansão das universidades federais (Reuni). Brasília, 2007a. Diário Oficial da União, Brasília, 24 abr. 2007.

Decreto n. 7.352, de 04 de dezembro de 2010. Dispõe sobre a política de educação do campo e o Programa Nacional de Educação na Reforma Agrária - Pronera. Brasília, 2010. Disponível em: <http://www.planalto.gov.br/ccivil_03/_ato2007-2010/2010/decreto/ d7352.htm>. Acesso em: 17 mar. 2015.

Lei n. 11.494, de 20 de junho de 2007. Regulamenta o Fundo de Manutenção e Desenvolvimento da Educação Básica e de Valorização dos Profissionais da Educação FUNDEB. Brasília, 2007b.

Ministério da Educação (MEC). Conselho Nacional de Educação (CNE). Câmara de Educação Básica (CEB). Resolução n. 1, de 03 de abril de 2002. Diretrizes Operacionais para Educação Básica nas Escolas do Campo. Brasília, 2002.

Ministério da Educação (MEC). Conselho Nacional de Educação (CNE). Conselho Pleno (CP). Parecer n. 9 de 2001. Diretrizes Curriculares Nacionais para formação de professores da Educação Básica, em nível Superior, curso de licenciatura de Graduação plena. Diário Oficial da União, Brasília, 2001.

Portaria n. 1 de 2 de janeiro de 2014. Instituiu o Grupo de Trabalho, GTProcampo. Brasília, 2014b.

- Secretaria de Ensino Superior (SESu). Secretaria de Educação Profissional e Tecnológica (Setec). Secretaria de Educação Continuada Alfabetização Diversidade e 
Inclusão (Secadi). Edital n. 2, de 31 de agosto de 2012. Chamada Pública para seleção de Instituições Federais de Educação Superior - IFES e de Institutos Federais de Educação, Ciência e Tecnologia - IFET, para criação de cursos de Licenciatura em Educação do Campo, na modalidade presencial. Brasília, 2012.

BRESSER-PEREIRA, Luiz Carlos. Plano Diretor da Reforma do Aparelho do Estado. Presidência da República, Câmara da Reforma do Estado. Brasília, 1995. Disponível em: <http://www.bresserpereira.org.br/documents/mare/planodiretor/planodiretor.pdf.>. Acesso em: 12 mar. 2016.

BRITO, Márcia Bittencourt. $\mathbf{O}$ acesso à educação superior pelas populações do campo, na universidade pública: um estudo do Pronera, Procampo e Parfor, na Universidade Federal do Pará. 2013. Dissertação (Mestrado em Educação) - PPGED-UFPA, 2013.

CALDART, Roseli Salete. Apresentação. In: PISTRAK, M. M. Fundamentos da Escola do Trabalho. 3. ed. São Paulo: Expressão Popular, 2011. p. 3-4.

CONFERÊNCIA NACIONAL DE EDUCAÇÃO DO CAMPO (CNEC): Por uma Política Pública de Educação do Campo. 2., 2004. Luziânia-GO. Texto Base... LuziâniaGO, 2-6 ago. 2004.

FÓRUM NACIONAL DE EDUCAÇÃO DO CAMPO (FONEC). Documento resultante do III Seminário Nacional. Brasília: Fórum Nacional de Educação do Campo, ago. 2015. (digitalizado)

. Nota Técnica: GT-Procampo. Brasilia: Fórum Nacional de Educação do Campo, 2014.

. Manifesto à sociedade brasileira. Brasília: Fórum Nacional de Educação do Campo, 21 ago. 2012.

INSTITUTO BRASILEIRO DE GEOGRAFIA E ESTATÍSTICA (IBGE). Indicadores educacionais. Brasil, 2010.

INSTITUTO NACIONAL DE ESTUDOS E PESQUISAS EDUCACIONAIS (INEP). Censo Escolar. Brasil, 2011. Disponível em: <http://www.inep.gov.br>. Acesso em: 20 dez. 2015.

Indicadores educacionais. Brasil, 2013. Disponível em: <http://www.inep.gov. br>. Acesso em: 12 de janeiro de 2016.

MANCEBO, Deise. Educação Superior no Brasil: expansão e tendências (19952014). In: REUNIÃO NACIONAL DA ANPEd, 37. 2015. Anais... Florianópolis: UFSC, 2015. p. 7-8.

MOLINA, Mônica C; HAGE, Salomão. Política de formação de educadores do campo no contexto da expansão da educação superior. Revista Educação em Questão, Natal, v. 51, n. 37, p. 121-146, jan./abr. 2015.

MOLINA, Mônica C; SÁ Laís Mourão. Verbete da Escola do Campo. In: CALDART, Roseli Salete; PEREIRA, Isabel Brasil; ALENTEJANO, Paulo; FRIGOTTO, Gaudêncio (Org.). Dicionário da Educação do Campo. Rio de Janeiro, São Paulo: Escola Politécnica de Saúde Joaquim Venâncio: Expressão Popular, 2012.

- A produção do conhecimento na formação dos educadores do campo. Revista em

Aberto, Brasília, v. 24, n. 86, p. 61-96, 2011.

PISTRAK, M. M. Fundamentos da Escola do Trabalho. 3. ed. São Paulo: Expressão Popular, 2011.

SEMINÁRIO NACIONAL DAS LICENCIATURAS EM EDUCAÇÃO DO CAMPO. 4. 2014. Caderno do Procampo. Belém-PA: MEC/Secadi/UFPA, 2014.

SGUISSARDI, Waldemar. Relatório do estudo diagnóstico da política de expansão da 
(e acesso à) educação superior no Brasil 2002-2012. Piracicaba: UFSCAR, 2014.

UNIVERSIDADE FEDERAL DO PARÁ (UFPA). Faculdade de Educação e Faculdade de Ciências Agrárias e Naturais. Licenciatura em Educação do Campo. Projeto Pedagógico Do Curso (PPC). Cametá-PA: UFPA, 2013.

\section{NOTAS}

${ }^{1}$ A reforma do Estado deve ser entendida dentro do contexto da redefinição do papel do Estado, que deixa de ser o responsável direto pelo desenvolvimento econômico e social pela via da produção de bens e serviços para fortalecer-se na função de promotor e regulador desse desenvolvimento. Cf.: BRESSER-PEREIRA, 1995. Disponível em: <http://www. bresserpereira.org.br/documents/mare/planodiretor/planodiretor.pdf $>$. Acesso em: 12 mar. 2016.

${ }^{2}$ Conceito utilizado por Sguissardi (2014) quando analisa a expansão da educação superior brasileira apontando os elementos de ajuste desta ao neoliberalismo.

${ }^{3}$ Dos Institutos Federais que tiveram seu projetos aprovados destacamos: Instituto Federal do Maranhão (IFMA), Instituto Federal do Mato Grosso (IFMT), Instituto Federal de Santa Catarina (IFSC), Instituto Federal Farropilha e Instituto Federal de Minas Gerais (IFMG). Todos foram aprovados por meio do edital no 02/2012 - SESu/Setec/Secadi.

${ }^{4}$ Os seminários nacionais de Licenciatura em Educação do Campo têm ocorrido desde 2008 e em 2015 encontram-se em sua quinta versão, tendo como objetivo debater os aspectos político e pedagógico do Procampo, considerando suas especificidades no que se refere à organização curricular; às áreas de conhecimentos, à Alternância Pedagógica e ao processo de implementação e consolidação do curso em seus diversos contextos. Em 2015 realizouse em Belém do Pará o Círculo de Formação em Alternância Pedagógica, que teve como objetivo ampliar as discussões e a partilha de experiências visando à consolidação do curso de Licenciatura em Educação do Campo.

Submetido: 04/04/2016

Aprovado: 22/08/2016

Contato:

Salomão Antônio Mufarrej Hage

Avenida Alcindo Cacela, no 1625. Bairro São Brás

Belém |PA|Brasil

CEP 66.040-020 